\title{
KEARIFAN LOKAL PADA BUDAYA CYBER-FANDOM
}

\author{
LOCAL WISDOMS IN CYBER-FANDOM CULTURE
}

\section{Rina Soraya Fakhriati Effendi}

\author{
Program Studi Magister Ilmu Komunikasi Pascasarjana Universitas Islam Bandung \\ E-mail:fakhri.rina@gmail.com
}

\begin{abstract}
In understanding cyber-fandom, it is necessary to research the culture that exist in the online fandom community. Cyber-fandom Viking Persib Club is done through@officialvpc account. The community that was formerly a Sundanese cultural background, currently has diverse cultural backgrounds. This research aims to identify the context of @officialvpc tweets in Sundanese culture perspective, then identify the interactions of@officialvpc in Sundanese culture perspective, and identify the reality in offline with the relations to online realm of @officialvpc in Sundanese culture perspective. This research utilizes Qualitative method with Netnography approach and using Social Construction of Reality Theory.The results show the local cultural wisdom of Sunda contained in the context of @officialvpc tweets are "Nyaur kudu diukur, nyabda kudu diungang", "Ulah ngaliarkeun taleus ateul", "Ulah pagiri-giri calik, ulah pagirang-girang tampian" and "ka cai kudu saleuwi ka darat kudu salebal". The local cultural wisdom of Sunda contained in interactions of @officialvpc is "kudu puguh bule hideungna”,. And the local cultural wisdom of Sunda contained in reality in offline with the relations to online realm of@officialvpc is "Hana nguni hana mangke, tan hana nguni tan hana mangke, aya ma beuheula aya tu ayeuna, hanteu ma beuheula hanteu tu ayeuna. Hana tunggak hana watang, tan hana tunggak tan hana watang. Hana ma tunggulna aya tu catangna”.
\end{abstract}

Keywords: Sundanes Culture, Fandom, Social Media, Netnography.

\begin{abstract}
Abstrak. Dalam mempelajari cyber-fandom, perlu dilakukan penelitian mengenai budaya yangterdapat pada komunitas fandom online. Cyber-fandom Viking Persib Club dilakukan melalui akun@officialvpc. Komunitas yang sebelumnya berlatar belakang budaya Sunda, saat ini memiliki latar belakang budaya yang beragam. Penelitian bertujuan untuk mengetahui konteks yang terdapat pada teks kicauan akun twitter@officialvpc dalam perspektif budaya Sunda, mengetahui interaksi yang terjadi pada akun twitter@officialvpc dalam perspektif budaya Sunda, mengetahui realitas yang terjadi dalam ruang offline serta keterkaitannya dengan ruang online akun@officialvpc dalam perspektif budaya Sunda. Penelitian menggunakan metode Kualitatif, pendekatan Netnografi dengan Teori Konstruksi Realitas Sosial. Hasil penelitian menunjukkan kearifan budaya lokal Sunda yang terdapat pada konteks kicauan akun twitter@officialvpc adalah "Nyaur kudu diukur, nyabda kudu diungang", "Ulah ngaliarkeun taleus ateul”, "Ulah pagiri-giri calik, ulah pagirang-girang tampian", dan "Ka cai kudu saleuwi ka darat kudu selebak”. Kearifan budaya lokal Sunda yang terdapat pada interaksi yang terjadi padaakun@officialvpc adalah "Kudu puguh bule hideungna”. Dan kearifan budaya lokal Sunda yang terdapat pada realitas yang terjadi dalam ruang offline serta keterkaitannya dengan ruang online akun@officialvpc adalah "Hana nguni hana mangke, tan hana nguni tan hana mangke, aya ma beuheula aya tu ayeuna, hanteu ma beuheula hanteu tu ayeuna. Hana tunggak hana watang, tan hana tunggak tan hana watang. Hana ma tunggulna aya tu catangna”.
\end{abstract}

Kata kunci: Budaya Sunda, Fandom, Media Sosial, Netnografi 


\section{Pendahuluan}

Twitter tidak lagi digunakan untuk jejaring pertemanan semata, namun juga menunjukkan adanya budaya penggemar (fadom) yang muncul dalam realitas siber. Budaya fandom yang terjadi pada dunia siber (cyber-fandom) terjadi karena pada dasarnya secara faktor sosiologis, manusia memiliki ketertarikan terhadap kelompok-kelompok sosial dimana setiap anggotanya dapat mengekspresikan kepentingan bersama, apakah kepentingan tersebut berhubungan dengan selera musik, agama, olahraga dan masih banyak lagi. Keberadaan media sosial secara signifikan dapat meningkatkan kemampuan mereka untuk berkomunikasi satu sama lain, juga bersama objek yang digemarinya.

Komunitas Viking Persib Club merupakan salah satu komunitas yang memanfaatkan media sosial dalam melakukan kegiatan fandomnya, salah satunya melalui akun twitter @officialvpc. Komunitas tersebut pada awalnya didirikan di Bandung, dengan anggota yang mayoritas memegang budaya Sunda. Adanya media sosial telah meningkatkan kemampuan komunitas tersebut dalam berkomunikasi,

dan juga telah mengubah gagasan mereka terhadap ruang dan waktu. Melalui media sosial keanggotaan komunitas pun mulai menyebar ke mancanegera, saat ini anggotanya tidak hanya berlatar belakang budaya Sunda saja, namun juga dengan latar belakang budaya yang berbedabeda. Konsep dari "Komunitas Virtual” (Rheingold, 1993:5) menyebutkan bahwa komunitas tidak perlu berasal dari sebuah tempat yang sama secara geografis. Semua orang di dunia ini melalui dukungan interaksi elektronik bisa menjadi tetangga "Virtual" melalui internet. Teman, komunitas, dan jaringan profesional, saat ini dapat terjadi di dunia virtual tanpa harus bertatap muka.

Kozinets dalam bukunya yang berjudul Netnography: Doing Ethnographic Research Online yang diterbitkan tahun 2010 menyatakan bahwa komunitas- komunitas online membentuk dan mengejawantahkan nilai-nilai, adat kebiasaan dan kepercayaan yang mengatur dan mengarahkan tingkah laku komunitas tersebut. (Kozinets, 2010:12). Singkatnya, walaupun interkasi sosial anggota komunitas dilakukan secara online dan dilakukan dalam ruang, waktu dan latar belakang budaya yang berbeda, namun tetap saja komunitas online dibentuk dari suatu kebudayaan. Berdasarkan fenomena tersebut, peniliti tertarik untuk meneliti budaya atau kearifan lokal yang terdapat pada aktivitas fandom online (cyber-fandom) yang dilakukan oleh komunitas Viking Persib Club.

Peneliti tertarik untuk mengungkapkan bagaimana kearifan budaya lokal Sunda yang terdapat dalam budaya cyber-fandom Bobotoh melalui akun twitter@officialvpc. Adapun tujuan dari penelitian ini adalah mengetahui konteks yang terdapat pada teks kicauan akun twitter@officialvpc dalam perspektif budaya

Sunda, mengetahui interaksi yang terjadi pada akun twitter @officialvpc dalam perspektif budaya Sunda dan mengetahui realitas yang terjadi dalam ruang offline serta keterkaitannya dengan ruang online akun@officialvpc dalam perspektif Budaya Sunda. 


\section{Metode}

Penelitian ini menggunakan metode kualitatif dengan pendekatan netnografi. Dalam buku Netnography, netnografi didefinisikan sebagai "sebuah bentuk etnografi yang diadaptasi untuk dunia sosial yang dimediasi perangkat komputer (Kozinets, 2010:1). Singkatnya, netnografi adalah sebuah metode untuk mempelajari cybernetics space (cyberspace). Belakangan ini netnografi telah diusung sebagai satu-satunya metode yang secara khusus dirancang untuk mempelajari kebudayaan dan komunitas online (Bowler Jr, 2010) dalam (Hidayah, 2012:6).

Terdapat beberapa tahapan penelitian netnografi yang dilakukan dalam penelitian ini, di antaranya adalah: 1) Planning and Entree. Pada tahap ini peneliti masuk ke dalam budaya online dan ikut berpartisipasi di dalamnya, peneliti menetukan apa dan siapa yang akan diteliti, bagaimana cara menelitinya, bagaimana peneliti harus merepresentasikan diri dalam penelitian, bagaimana caranya penelitian ini dapat dilakukan secara etis, dan seberapa besar gangguan yang akan muncul di dalam komunitas yang diteliti, akibat adanya penelitian ini. Peneliti mulai membuat pertanyaan penelitian, mencari dan membaca studi penelitian sejenis lainnya dan mencari aplikasi online yang tepat untuk dijadikan tempat penelitian. 2) Data Collection. Pada tahap ini peneliti melakukan partisipasi dengan aktif agar terlihat oleh anggota komunitas. Dalam mengumpulkan data, peneliti menggunakan cara memotret gambar yang muncul di layar komputer secara langsung, atau sering disebut dengan online data capture. Setelah data dikumpulkan, kemudian data diarsipkan. Data yang diarsipkan adalah kicauan dari akun@officialvpc mulai bulan Oktober 2016 sampai dengan
Desember 2016. Selanjutnya peneliti melakukan wawancara online. Wawancara dilakukan melalui aplikasi yang mudah diakses dan memiliki daya simpan pesan yang cukup lama, yaitu email, aplikasi WhatsApp dan aplikasi Line. Peneliti juga mengambil catatan lapangan dari data tekstual (misalnya email) dan data non-tekstual (misalnya wiki).

3) Data Analysis. Pada tahap ini peneliti menerjemahkan kode, mencatat, membuat abstrak dan membandingkan data, memeriksa data dan memperbaiki jika ada kekeliruan, kemudian menguraikan seperangkat generalisasi yang dapat menjelaskan kekokohan dari data yang dimiliki dan terakhir data yang sudah digeneralisasi kemudian disesuaikan dengan teori yang digunakan. 4) Conducting Ethical Netnography. Pada tahap ini, peneliti memastikan bahwa langkah-langkah penelitian yang sudah dilakukan tidak melanggar etika-etika yang ada, misalnya menjaga kerahasiaan informasi dari informan dan memastikan mencantumkan sumber data pada setiap gambar dan kutipan. 5) Representation and Evaluation. Pada tahap ini, peneliti mengevaluasi kembali hasil dari penelitian yang dilakukan dengan pedoman sepuluh kriteria dalam mengevaluasi kualitas dalam penelitian netnografi (Koherensi, Kekakuan, Literasi, Groundedness, Inovasi, Resonansi, Verisimilitude, Refleksivitas, Praxis dan Intermix).

\section{Temuan dan Pembahasan}

Dalam proses komunikasi melalui twitter, terdapat sebuah kerja kognitif individu untuk menafsirkan realitas yang ada, karena pada komunikasi yang dilakukan melalui media sosial, terjadi relasi sosial antara individu dengan lingkungan atau pengguna lain di sekitarnya. Individu tersebut kemudian membangun sendiri 
pengetahuan atas realitas tersebut berdasarkan pada struktur pengetahuan yang telah ada sebelumnya, inilah yang oleh Berger dan Luckmann disebut dengan konstruksi sosial.

Jika dikaitkan dengan penelitian ini, dimana peneliti mencoba meneliti realitas cyber-fandom yang terdapat pada Bobotoh, Bobotoh membangun realitas fandomnya berdasarkan pengetahuan lokal mereka mengenai klub sepak bola Persib, dan juga berdasarkan pengalaman yang mereka dapatkan melalui relasi sosial dengan sesama supporter, dengan opinion leader dan dengan objek yang mereka gemari melalui twitter.

Teori Konstruksi Realitas Sosial yang merupakan teori dari paradigma konstruktivis ini melihat realitas sosial sebagai konstruksi sosial yang diciptakan oleh individu, yang merupakan manusia bebas. Dalam hal ini, Bobotoh menjadi penentu dalam dunia sosial yang dikonstruksi berdasarkan kehendaknya. Mereka dapat menciptakan realitas sosial yang relatif bebas di dalam dunia sosialnya.

Jika dikaitkan dengan realitas cyber-fandom Bobotoh melalui akun twitter@officialvpc, dan sejalan dengan analisis realitas sosial siber yang dirancang oleh Gotved, maka ketiga tahapan tersebut dapat dilihat sejak admin memposting teks berupa twit yang kaya akan konteks, kemudian terjadinya interaksi antara admin dengan lingkungan sekitar, dan proses penyerapan kembali dunia objektif oleh admin berupa kesesuaian pengetahuan antara dunia offline dan online dari komunitas yang diwakili oleh admin.

\section{Konteks yang Terdapat pada Teks Kicauan Akun Twitter (a) officialvpc dalam Perspektif Budaya Sunda}

Secara garis besar, terdapat tiga konteks pada kicauan akun @officialvpc, konteks-konteks tersebut sesuai dengan tiga wujud kebudayaan yang diutarakan oleh Koentjaraningrat. Wujud kebudayaan menurut Koentjaraningrat, yang pertama berbentuk ide atau gagasan, yang kedua berbentuk aktivitas yang dilakukan setiap waktu dan membentuk pola-pola tertentu berdasarkan adat yang berlaku dalam masyarakat atau komunitas tertentu, dan yang ketiga kebudayaan fisik. (Koentjaraningrat, 2003: 186)

\section{Ide atau Gagasan}

Konten yang diposting melalui akun tersebut, baik ide dan gagasannya murni merupakan ide dan gagasan dari admin, walaupun pada dasarnya dibatasi beberapa peraturan tidak tertulis. Selain menjadi refleksi komunitas, akun ini dikelola oleh admin yang memiliki pengetahuan Budaya Sunda yang cukup baik, terlihat ada upaya admin dalam menjaga kekhasan Budaya Sunda dalam setiap twit yang disampaikan. Admin membuat karakter Sunda yang cukup dalam ketika mengelola akun @officialvpc, walaupun bahasa yang digunakan tidak selalu Bahasa Sunda, namun admin selalu menggunakan bahasa yang relatif lebih santun jika dibandingkan dengan akun-akun fandom lainnya. Kritik pun biasanya disampaikan dengan kalimat sindiran, tidak secara frontal dengan menggunakan bahasa yang keras seperti akun-akun fandom kebanyakan.

Jika dikaitkan dengan kearifan budaya lokal Sunda, hal tersebut mencerminkan karakter personal orang Sunda, yaitu "Nyaur kudu diukur, nyabda kudu diungang", yang artinya harus menjaga ucapan, tindakan atau perbuatan agar tidak menyakiti orang. Adanya upaya dari admin @officialvpc untuk menyampaikan ide tanpa menyinggung pihak lain, sesuai dengan ungkapan Sunda "Ulah ngaliarkeun 
taleus ateul" yang artinya jangan menyebarkan perkara yang dapat menimbulkan keburukan atau keresahan.

\section{Aktivitas}

Kemudian untuk konteks aktivitas, setiap aktivitas yang diposting melalui akun@officialvpc selalu mewakili aktivitas yang dilakukan Komunitas Viking Persib Club di dunia nyata, baik itu aktivitas yang berhubungan dengan pihak internal komunitas maupun aktivitas yang melibatkan pihak eksternal komunitas. Dari hasil observasi dan wawancara, peneliti mendapatkan kesimpulan bahwa aktivitas-aktivitas tersebut diposting untuk memberikan informasi kepada followers mengenai aktivitasaktivitas yang dilakukan komunitas Viking Persib Club, namun tidak seluruh aktivitas diposting melalui akun @officialvpc, admin memilih aktivitasaktivitas mana yang akan diposting dan mana yang tidak. Karena akun tersebut mewakili komunitas, maka ada proses sortir yang dilakukan oleh admin, adapun pemilihan konten aktivitas ini dilakukan dengan alasan untuk menjaga hubungan baik dengan pihak internal maupun eksternal komunitas, terkadang konten aktivitas yang diposting oleh admin tidak selalu sesuai dengan keinginan sebagian Bobotoh. Jika dipandang dari persepektif Budaya Sunda, adanya proses sortir yang dilakukan oleh admin dalam pemostingan aktivitas dengan tujuan menjaga hubungan (citra) di mata pihak internal dan eksternal, berhubungan dengan karakter orang Sunda yang selalu menjaga hubungan dengan orang lain, baik dalam lingkungan terkecil ataupun dengan lingkungan di sekitarnya. Tercermin dalam ungkapan "Ulah pagiri-giri calik, ulah pagiranggirang tampian" artinya jangan ada permusuhan di antara manusia.

\section{Produk}

Untuk konteks produk yang terdapat dalam teks atau twit yang diposting di akun@officialvpc. Akun @officialvpc memposting produkproduk yang berkaitan dengan kesekretariatan dan rekrutmen anggota baru, admin menganggap twitter sebagai media yang tepat untuk mempublikasikan produk tersebut kepada followers. Selain itu pada waktu-waktu tertentu admin juga meretweet iklan-iklan produk dari Viking Fanshop. Viking Fanshop adalah salah satu bentuk aktivitas dari Komunitas Viking yang bergerak dibisnis properti supporter. Posting produk tersebut selain memiliki tujuan bisnis, juga memiliki tujuan kolektivitas, karena produk yang didesain khusus menggunakan simbolsimbol komunitas, dijadikan identitas bagi penggunanya sebagai anggota Komunitas Viking. Kolektivitas merupakan ciri masyarakat Sunda, sesuai dengan karakter " $k a$ cai $k u d u$ saleuwi ka darat kudu selebak" yang arti utamanya adalah kebersamaan.

\section{Interaksi yang Terjadi pada Akun Twitter@officialvpc dalam Perspektif Budaya Sunda}

Interaksi yang peneliti temukan melalui akun@officialvpc terdapat tiga jenis, yaitu interaksi dengan sesama akun fandom, interkasi dengan akun personal Bobotoh dan interaksi dengan objek yang digemari. Dalam setiap jenis interkasi tersebut kadang kala terjadi konflik. Cara penyelesaian konflik yang admin lakukan akan menentukan baik atau buruknya hubungan dan interkasi di antara admin dengan followersnya.

Masing-masing jenis konflik memiliki cara penanganannya yang berbeda- beda. Menurut observasi dan 
wawancara yang sudah peneliti lakukan, admin cenderung lebih memperhatikan konflik dan penyelesaian konflik yang terjadi dengan sesama akun fandom. Adapun penyebab konflik biasanya terjadi karena kurangnya koordinasi di antara akun fandom, cara penyelesaiannya biasanya dilakukan melalui timeline, namun jika tidak terdapat jalan keluar, maka dilakukan mediasi pada dunia nyata. Admin menganggap konflik yang terjadi dengan akun personal tidak lebih karena perbedaan persepsi, sehingga admin membiarkan konflik tersebut berlalu begitu saja tanpa ada penyelesaian. Sedangkan untuk konflik dengan objek yang digemari biasanya terjadi hanya satu arah, akun dari objek yang digemari sebagian besar tidak menanggapi (via timeline) apabila terjadi konflik.

Sikap admin yang cenderung mengahulukan konflik dan penyelesaian konflik dengan akun sesama fandom mencerminkan karakter budaya Sunda, yaitu budaya kolektivitas. Cara penyelesaian konflik yang sesuai dengan prosedur juga mencermikan karakter pribadi Orang Sunda, "Kudu puguh bule hideungna", yang artinya perkara itu harus jelas aturannya bila ingin mengambil tindakan.

\section{Realitas yang Terjadi dalam Ruang Offline Serta Keterkaitannya dengan Ruang Online Akun@officialvpc dalam Perspektif Budaya Sunda}

Terdapat dua jenis realitas yang terjadi dalam ruang offline serta keterkaitannya dengan ruang online akun@officialvpc. Keterkaitan tersebut sering kali membentuk pola timbal balik di antara ruang offline dan ruang online, artinya realitas yang terjadi di ruang offline dapat memengaruhi ruang online, dan selanjutnya apa yang terjadi di ruang online tersebut akan memengaruhi kembali realitas yang terjadi di ruang offline, dan begitupun sebaliknya.

Salah satu contohnya adalah ketika terjadi konflik di antara komunitas Viking Persib Club dengan Bonek. Diawali dengan kekecewaan Bonek terhadap sikap Umuh Muchtar pada kongres PSSI, yang kemudian bergeser menjadikonflik di ruang online akun@officialvpc. Upaya penyelesaian konflik yang dilakukan oleh admin @officialvpc, kemudian berpengaruh pada ruang offline komunitas Viking Persib Club, mendorong anggota komunitas untuk melakukan aksi nyata.

Melihat pola keterkaitan yang terjadi secara timbal balik (berputar) di antara realitas offline dan realitas online komunitas Viking, maka dapat dilihat cara pandang komunitas tersebut mengenai konsep waktu, artinya budaya cyber-fandom komunitas Viking Persib Club dibangun dari realitas yang sudah terjadi sebelumnya di dunia nyata, untuk kemudian membentuk suatu feedback (timbal balik) kembali bagi realitas offline komunitas pada waktu selanjutnya. Hal tersebut sesuai dengan pola pikir masyarakat Sunda "Hana nguni hana mangke, tan hana nguni tan hana mangke, aya ma beuheula aya tu ayeuna, hanteu ma beuheula hanteu tu ayeuna. Hana tunggak hana watang, tan hana tunggak tan hana watang. Hana ma tunggulna aya tu catangna." Artinya: Ada dahulu ada sekarang, bila tak ada dahulu tak akan ada sekarang, karena ada masa silam maka ada masa kini, bila tak ada masa silam takan ada masa kini. Ada tunggak tentu ada batang, bila tak ada tunggak tak akan ada batang, bila ada tunggulnya tentu ada batangnya.

\section{Simpulan dan Saran}

Berdasarkan hasil penelitian yang telah diuraikan di atas, maka peneliti menarik kesimpulan sebagai 
berikut:

1. Terdapat tiga konteks pada teks atau kicauan yang diposting oleh admin akun@officialvpc, yaitu konteks ide atau gagasan, konteks aktivitas dan konteks produk. Konteks ide yang mengandung kearifan budaya lokal Sunda adalah adanya upaya admin akun@officialvpc dalam menjaga karakter Sunda dan berhati-hati dalam penggunaan bahasa, sesuai dengan ungkapan Sunda "Nyaur kudu diukur, nyabda kudu diungang", yang artinya harus menjaga ucapan, tindakan atau perbuatan agar tidak menyakiti orang dan adanya upaya dari admin@officialvpc untuk menyampaikan ide tanpa menyinggung pihak lain, sesuai dengan ungkapan Sunda "Ulah ngaliarkeun taleus ateul" yang artinya jangan menyebarkan perkara yang dapat menimbulkan keburukan atau keresahan. Konsep aktivitas mengandung kearifan budaya lokal Sunda. Adanya pemilihan konten aktivitas yang akan diposting di akun@officialvpc, dengan tujuan menjaga hubungan baik dengan segala pihak, sesuai dengan ungkapan Sunda "Ulah pagiri-giri calik, ulah pagirang-girang tampian" artinya jangan ada permusuhan di antara manusia. Konsep produk mengandung kearifan budaya lokal Sunda. Dipostingnya konten produk dengan desain yang kental dengan ciri khas komunitas, bertujuan agar dapat dibeli oleh anggota untuk dijadikan identitas sebagai anggota komunitas, menggambarkan adanya budaya kolektivitas dan sesuai dengan ungkapan Sunda "ka cai kudu saleuwi ka darat kudu selebak" yang arti utamanya adalah kebersamaan.

2. Interaksi yang terjadi pada akun twitter@@officialvpc mengandung kearifan budaya lokal Sunda. Adanya aturan yang jelas dan kesesuaian cara admin dalam menyelesaikan konflik yang terjadi baik dengan sesama akun fandom, dengan akun personal Bobotoh dan dengan objek yang digemari, sesuai dengan ungkapan Sunda "Kudu puguh bule hideungna", yang artinya perkara itu harus jelas aturannya bila ingin mengambil tindakan.

3. Realitas yang terjadi dalam ruang offline serta keterkaitannya dengan ruang online akun@officialvpc, mengandung kearifan lokal Budaya Sunda. Adanya keterkaitan di antara ruang offline dan online yang membentuk pola timbal balik, memperlihatkan cara komunitas dalam memandang suatu masalah, dimana komunitas memberikan perhatian terhadap kejadian yang terjadi lebih dulu terjadi, dan kemudian menjadi feedback untuk kejadian selanjutnya. Sesuai dengan ungkapan Sunda ""Hana nguni hana mangke, tan hana nguni tan hana mangke, aya ma beuheula aya tu ayeuna, hanteu ma beuheula hanteu tu ayeuna. Hana tunggak hana watang, tan hana tunggak tan hana watang. Hana ma tunggulna aya tu catangna." Artinya: Ada dahulu ada sekarang, bila tak ada dahulu tak akan ada sekarang, karena ada masa silam maka ada masa kini, bila tak ada masa 
silam takan ada masa kini. Ada tunggak tentu ada batang, bila tak ada tunggak tak akan ada batang, bila ada tunggulnya tentu ada batangnya.

Berdasarkan penelitian yang dilakukan, peneliti mengajukan saransaran sebagai berikut:

1. Konteks dari kicauan yang disampaikan oleh admin dapat dimengerti oleh followers dengan baik. Diharapkan admin tetap mempertahankan karakternya dalam memposting konten, sehingga akun @ officialvpc tetap menjadi salah satu akun referensi untuk Bobotoh.

2. Aktivitas yang diposting admin saat ini sudah cukup mewakili aktivitas dari Komunitas Viking Persib Club, diharapkan admin konsisten dalam melakukan posting aktivitas komunitas, terutama pada aktivitas-aktivitas yang bermanfaat bagi followers pada umumnya.

3. Keterkaitan di antara realitas siber dan realitas nyata pada akun@officialvpc sangat terlihat jelas. Diharapkan konten yang diposting oleh admin selalu sejalan dengan realitas nyata Komunitas Viking Persib Club, sehingga akun@officialvpc tetap dapat merepresentasikan Komunitas Viking Persib Club di dunia siber.

4. Dalam penelitian Netnografi, ada tuntutan bagi peneliti untuk melakukan wawancara secara online, disarankan untuk peneliti selanjutnya untuk menggunakan media online yang sifatnya realtime, seperti aplikasi Skype.

5. Penelitian ini dapat dijadikan sebagai bahan rujukan, tanpa melupakan nilai keaslian dalam penelitian di bidang Ilmu Komunikasi, khususnya penelitian mengenai komunikasi budaya maupun penelitian mengenai media baru dan realitas yang ada di dalamnya.

\section{Daftar Pustaka}

Hidayah, Sita. 2012. Antropologi Digital dan Hipertext: Sebuah Pembahasan Awal. RANAH Jurnal Mahasiswa Antropologi Universitas Gadjah Mada Tahun 2012 Ed April

Koentjaraningrat. 2003. Pengantar Antropologi I. Jakarta: Rineka Cipta Kozinets, R. V. 2010. Netnography. Doing ethnographic research online. Thousand Oaks, CA: SAGE Publications

Rheingold, Howard. 1993. The Virtual Community. Boston: AddisonWesley Publishing Company 